\title{
Philosophical Issues of Education for the Information Society
}

\section{Vladimir Kinelev}

\author{
v.kinelev@gmail.com, UNESCO Chair “Knowledge Society and New Information Technologies,” Moscow, \\ Russia
}

Abstract: Philosophical and methodological issues of the use of information and communication technologies in science and education as one of the prime strategic challenges for the Information society are considered.

Keywords: Information society, fundamental education, current problems of modern sciences

\section{Relevance of the Problem}

The advent of the new millennium should not be perceived as just another divide in the calendar of history. It is a major divide, which urges us to reflect on the past and try to discern the contours of the future.

When discussing global issues of social and economic development, including education and science, that humanity will have to address in the $21^{\text {st }}$ century, we must first answer the questions: What is the significance of the age as the prelude for the new era? Which part of its legacy will be carried over into the future, and which will be left behind?

I hope to be correct in suggesting that one of the defining features of contemporary life and increasingly of the future is the accelerated pace of change. The world never stands still. Moreover, its swift changeability has been turned into a constituent feature of global historical development.

The current pace and magnitude of change break the traditional framework of historical gradations. For the first time in the history of our civilization, generations of products and ideas come and go faster than generations of people succeed one another. It is important to note that changeability reveals itself through earlier unparalleled diversity, making it impossible to define our era through any single event or development in the life of society.

The historically unprecedented combination of changeability, a quickly growing technosphere, and new risks and contradictions in the development of human civilization set the task of searching for the possible ways of its further evolution. Many modern thinkers contend that humanity is undergoing a phase of cultural transition. It is characterised by the following significant factors. First, humanity is striving to forge a new basis for unity. It involves not only a single world market or a unified political order, but embraces a growing spiritual unity within diversity of peoples and cultures. Second, a new image of science is taking shape. Science attempts to find new sources for universality by overcoming the traditional alienation of the natural sciences from the humanities. Third, the relationship between the human civilization and nature is being redefined. And, finally, fundamental restructuring of education is taking place worldwide. To meet the requirements of the cultural transitional period, the educational sphere absorbs and passes over to the younger generation the characteristic elements of this transition, such as new humanism, a new image of science, and a new understanding of relationship between civilization and nature.

This transitional period coincides with an active phase of intensifying the process of globalization that embraces not only the economic and financial fields, but all spheres of human activities. The development of new information and communication technologies breaks through the territorial borders of nation states and makes geographical boundaries inadequate as delineations of jurisdictions. These technologies constitute a truly international and global realm of action, where it is practically impossible to successfully impose national laws and regulations. Information and communication technologies based on the Internet, telenetworks, and intelligent computer systems open up new and exciting opportunities for the free flow of knowledge and information across national boundaries. They build an environment of a new kind of knowledge that is beyond local and indigenous context. It is cross-cultural and tends to be characterized by a diversity in source, built on the basis of global infrastructure and depending on the following global domains of human ac- 
tivities: scientific and technical; political and economic; human and social; and cultural and educational. All of this enables us to talk about global knowledge and a new world community based on information - the Information Society.

The evolution of the Information Society will entail a dramatic change in production and business activities, as well as in a larger social context. Succeeding generations will face the challenge of adjusting to a new social environment wherein information and scientific knowledge will replace matter and energy as its pivotal factors and will define both society's strategic potential and prospects for its development.

It is important to note that the level of development and use of modern technologies is determined in different countries, to a large extent, by the degree of intellectual capacity building of each country, i.e., its society's ability to produce, consume, and apply scientific knowledge and new technology.

In these swiftly changing conditions of his/her life, a human being needs to develop the facility to enhance his/her professional skills and scientific knowledge on an ongoing basis. In other words, humanity must embrace and promote a culture of lifelong learning. Thus, scientific and technological progress and the global spread of scientific knowledge and information constitute the main arguments in favor of the leading role of education and science in the $21^{\text {st }}$ century.

\section{Educational Paradigm for a New Society}

Hence the questions: What will education for the emerging society be like? What demands should be made on education to help people adjust to the new, swiftly changing conditions of their life? What can be done today to meet these demands adequately?

These questions are a matter of serious concern for academics and state and public leaders of virtually all countries who are grappling with the task of modernizing and reforming national educational systems to transform their countries into learning economics and learning societies, inasmuch as the Information Society needs competent and knowledgeable citizens.

The Report of the International Commission on Education for the $21^{\text {st }}$ Century 'Learning: The Treasure Within' submitted to UNESCO stresses the crucial role of fundamental and thorough knowledge in allaying some major tensions that will pose formidable challenges in the third millennium.

The World Education Forum held in Dakar, Senegal, in April 2000, largely defined the contours of education capable to prepare people to live in the changing conditions of their life in the $21^{\text {st }}$ century. In accordance with them, the main features of education for the evolving society should be its high quality and open character.

Among the priorities associated with the creation of the necessary conditions for high quality of education, I would single out those related to the use of new pedagogical approaches in the educational process, greater focus on fundamental knowledge and development of an individual's creative potential, and the application of new information and communication technologies for teaching and learning.

As for using new pedagogical approaches in education, I believe that the distinguishing feature of this process shall be a shift of emphasis from "teaching" to "education."

To educate or to teach? Present-day educationalists often use these terms interchangeably as if they were absolute synonyms. In fact, "education" is not identical to "teaching," the difference lying in the quality of the result achieved. "Teaching" is geared towards the transfer of particular, and therefore limited, knowledge and skills. This approach has a long-standing tradition. The use of this method in conjunction with modern information technology has not helped free up talents and aptitudes of students so far, which is indicative of the fact that teaching as a form of transferring and accumulating knowledge is naturally handicapped. In other words, traditional teaching as a form of communicating knowledge is running out of potential.

In this context, "education," if broadly treated, may release new resources for the comprehensive development of an individual's creative potential and help the progress of science.

Unlike traditional teaching, education aims at forming a holistic picture of the world, thus shaping a versatile mind to respond adequately to the non-classical complexity of the world. It is this type of 
scientific knowledge that will enable an individual to perceive himself or herself as an integral part of the environment responsible for his/her harmonious relationship with nature and to appreciate science as a tool to achieve such harmony. For these purposes, a specificity of modern pedagogical approaches should consist in their ability not only to transfer knowledge to students, but to enable students to keep abreast with the ideas and discoveries, and develop their ingenuity through self-education. It is worth mentioning that scientific knowledge cannot be automatically assimilated by students. Nor can it just be passed on by the teacher to an inactive student, for it is generated by the student himself or herself as a result of his/her inner creative activity. It is a product of evolution and the self-orderliness of human intelligence. The teacher's role is to awaken the student's intellect, to shape an individual's creative potential and holistic world outlook, to show him or her models of holistic thinking.

So the educational paradigm for the evolving society can consequently be defined as a logically connected triad "From a holistic world to holistic knowledge, and via it to a holistic personality." This educational paradigm reflects, in my view, certain important requirements of human civilization at the dawn of the third millennium. Successful development of democracy and market economy and attainment of certain harmony among an individual, society, and nature appear feasible on the basis of broad fundamental and integral education that will enable people to cope with constant change throughout their lifetime.

The great saga of human knowledge contains pages that are unique, and I would first list among them those that contain examples of combining the potentials of the human mind and technology. The invention of printing raised the institutions of general education to a previously unattainable height. It was the first, and perhaps the highest ever, stage in the educational revolution. But I presume that it is not an exaggeration to contend that, considering the amazing standards and prospects of application offered by information and communication technologies in education, we are on the threshold of the next stage of the educational revolution, which will entail a dramatic shift in all spheres of education and science.

These circumstances and new social challenges, the new world community shaped by new information and communication technologies and patterns of action, call for a new kind of literacy for the Information Society. The new literacy demands a new technology for obtaining scientific knowledge, new pedagogical approaches for teaching and learning, new school curricula, and methodological materials for teachers and learners.

It is worth keeping in mind that ,for all the variety of information sources and teaching technologies that transform information into knowledge, there is only one way to convert knowledge into education. This conversion takes place in a human being's consciousness. Such understanding leads us to contend that no two educations of individuals can be treated as completely congruous, inasmuch as no two human personalities are alike, because each person is unique. The priority of a human personality was the main result of the past century. The priority of a human personality is the main imperative of the $21^{\text {st }}$ century.

Thus, it goes without saying that bearing, molding, and development of human capacity building in science and other spheres of a human being's activity, first of all, originate from education.

\section{Towards Fundamental Knowledge}

Of the main priorities associated with providing a high quality of education, I would single out the priority related to the "fundamentalization" of education.

The main reasons that stipulate the necessity of fundamentalization of education, in my opinion, can be divided into two groups. The first group of issues refers to the global problems in the evolution of human civilization.

It may be relevant to consider the fact that, in the process of development, an individual, society, the world community, and civilization as a whole reveal their essential, or fundamental, qualities and features. In this context, it is important to set up, on the basis of scientific picture of the world, an educational system that could be able to identify and transfer to students the most recent scien- 
tific developments. Moreover, students' attention should be drawn to the most essential - fundamental, stable, and lasting knowledge that lies at the core of the currently available scientific picture of the world. This includes the world of outer space, the world of a human being, and society, and the world of human civilization as well as fundamental global processes unfolding therein.

There is, however, another group of reasons pointing to the need of fundamentalizing education. It is derived from an understanding, increasingly shared by the world community, of the priority of an educated personality in the evolving society. In line with modern thinking, to nurture a broadlyeducated personality, a number of interconnected tasks should be solved. First, it is crucial to harmonize the individual's relations with nature by helping him/her obtain a scientific picture of the world. Second, it is important not to lose sight of the social nature of a human being, and, therefore, harmonious socialization should be accompanied by cultural assimilation through the study of history, literature, art, law, philosophy, and economics. Third, modern people live in a densely saturated information environment. So, the task facing the educational system is to teach him/her "to navigate" in it. And, last but not least, it is necessary that an individual should achieve sort of inner balance or harmony. Thus, the task of both solving the global problems of humankind and meeting the vital needs of individuals points to the idea of fundamental education.

The following question would seem to be relevant: What lies at the basis of fundamental education? Apparently, the emphasis is on fundamental sciences. However, before we get to the issue of fundamental education, it appears necessary first to develop a holistic perspective on fundamental sciences, per se. The fragmentation and differentiation of sciences in the $20^{\text {th }}$ century have reached a point where specialists working in different areas of what used to be a unified field of science no longer understand one another. It should be conceded, however, that more recently integrational and interdisciplinary approaches have been playing a more prominent role. And yet they are not very common. So, the task of scientists and educationalists is to identify the entirety of each of the fundamental sciences, then try to reveal the internal unity of the natural sciences as a whole with the entire body of humanitarian knowledge and, finally, at the next stage, to synthesize the principles of holistic fundamental education.

\section{ICTs and Society: Main Challenges}

The creation and expansion of information milieux have always been and still are an important and effective condition of progress in any society. From a historical perspective, information environments have impacted significantly on the acceleration of humanity's development and represented a decisive factor in improving most spheres of human activity: cultural, scientific, educational, and professional.

Why does the Information Society need new information and communication technologies? First of all, they are needed to meet large scale learning needs arising from social and economic development. For the first time in history, information and scientific knowledge are not simply a means of improving society, but are becoming the main products of the economy. Moreover, knowledge is the main asset and product of the Information Society upon which continued economic well-being and social development depend. Information and communication technologies are in the mainstream of these developments. Information and communication technologies are the means for providing access to and achievement of the continuous learning necessary for the successful participation of all social groups of the population in the Information Society.

As a result, learning can no longer be viewed as a ritual that one engages in only during the early part of a human being's life. Information and communication technologies allow us to exceed the traditional framework of the learning process. Being used to cross the age, time, and space barriers, they are bringing lifelong learning to all. People of every age, whatever they are doing, everywhere and in every environmental context are learning all the time. Thus, they comprise the Learning society. 
It is worth mentioning that the present level of development of information and communication technologies permits their successful application in education to release the creative potential of students. This owes to the more efficient organization of students' cognitive activities through the use of computers and the very important didactic characteristic of individualizing the classroom work without disrupting its entirety via programmed and adaptable curricula. It is important to note that we should take into account that new information technologies are better suited for adapting didactics to the mode of thinking that operates by association rather than via direct and consecutive notions. Therefore, it would be a mistake to think that the application of new information and communication technologies automatically improves the quality of education. In order to exploit the opportunities effectively, such fields as computer psychology, computer didactics, and computer ethics should be better developed, explored, and employed by educationists.

At the same time, I perceive considerable difficulties in shaping new education for the new generation. The main obstacle, from my point of view, is that we are trying to transfer our vision of how information and communication technologies should be used in education to a generation whose quite distinct mentality is in many ways different form ours. The reason for this is simple: we acquired and assimilated information and knowledge at a different age. Therefore, I have a feeling that the new generation employs the information received from us in a way that relates to their own world outlook, which can be very different from the one that we espouse.

When we talk about the role of information and communication technologies in education, we should proceed from the understanding that these technologies not only facilitate educational opportunities, but assist an individual in perfecting his/her perceptions, too. Modern information and communication technologies provide for learners richer information objects like images, videos, complex structures of knowledge, and their combinations, available via the Internet or other intelligent computer networks. Information and communication technologies radically extend possibilities for visualization, including visualization of the invisible, visualization in changed colors, and shapes.

Colorful pictures of works of architecture, sculptures, and paintings, grouped thematically and accompanied by cleverly made up texts and beautiful music, have a strong emotional effect on the student, develop his or her artistic taste, and, at the same time, enable the student to learn more about culture, art, and nature.

Parallel to education as a means of preparing students for life, cyberspace is developing as another educational milieu. The basic works of Vygotsky, Piaget, and Bruner gave rise to the term interiorization of physical objects, which suggests our creating "psychic" equivalents of the latter as "conceptual" models to be further used to construct variants of our own internal reality or virtual realities. Cyberspace prompts a reverse process, which could be called exteriorization; models of the physical world build up in the human mind and are let out into cyberspace. Thus, we should proceed on the understanding that it is necessary to develop, in an individual, a very special perception of his or her habitat, which comprises both: objects of the physical world and the ideas of these objects in the human mind, as well as the system of ideas in information space. It is the most interesting and mysterious interaction going on between psychic space and cyberspace.

Thus, information and communication technologies do not merely enhance intellect; they designate new dimensions of the human mind and open up vast and exciting perspectives of their use for capacity building in science via education.

The present level of development of information and communication technologies provides a realistic base for creating a global educational system as a basis for practical implementation of UNESCO's slogan "Learning without Frontiers."

In my view, there are two main obstacles that we have to overcome in order to create educational space without frontiers: geography and varying capacity to transmit, receive, and comprehend the same information by different people, particularly those with special needs. 
Distance learning helps education overcome the first barrier of space and time. Regardless of the physical distance, new information networks ensure the kind of direct communication between the teacher and the student, which has always been characteristic of full-time education, as well as its undeniable advantage.

It goes without saying that, in the near future, the development of information and communication technologies will result in a broad spread of so-called digital libraries, laboratories with remote access, open virtual universities, and global virtual campuses as the basis for a single educational and scientific environment serving the world community.

So, new information and communication technologies will bring about dramatic changes in the educational technologies of obtaining knowledge, its conversion into education, and realization of education through actions. Thus, the emerging Information Society calls for modern theory of distance learning, comprehending all its key areas such as: the policies and legal aspects; regulations and restrictions; appropriate organisational and pedagogical models of distance learning; its funding and effectiveness, professional staff development and management, technological infrastructure and quality assurance. I am convinced that, only then, distance learning will be able to provide a high quality and open education and to help people meet the challenges of the present $21^{\text {st }}$ century. I think that, in this very situation, one can say that a good theory is the best practical result.

It is worth mentioning that the development of information and communication technologies has a special meaning for those people who, due to various reasons, are unable to obtain education through other standard methods. It is of particular significance for people with special needs. New information technologies, as well as man-created artificial intellectual environments, have a capacity to, at least partially, return to many people the kind of abilities and communication possibilities that they may have been deprived of by nature, environmental disasters, military conflicts, or human violence.

I am confident that this is a two-way street, since, after demolishing the barriers of inter-human communication, so-called "ordinary people" will be able to obtain a broader impression of the essence of a human being and of the surrounding world. This seems to be the major humane tendency related to the use of information and communication technologies in education, science, and other spheres of practical and cultural activities of a human being.

\section{Conclusion}

Information and communication technologies have brought profound changes in society and education. They are so huge that new concepts of the society appeared: information society, learning society, and knowledge society. The changes are not only technological; they address the fundamental values and concepts of society and raise new essential questions. As part of addressing the educational challenges of the $21^{\text {st }}$ century, it is appropriate to define the tasks of education as a system of scientific knowledge, to overcome the traditional alienation of natural sciences from humanities, to find a new role of the teacher as the main agent of education. Information and communication technologies provide tremendous opportunities to narrow the socio-economic development gaps between countries and nations, giving all nations a new chance that they cannot miss.

\section{References}

Kinelev V.G. (1997). Education and Civilization. UNESCO, International Bureau of Education, Vol. XXVII, (pp. 371-383). Kinelev V.G. (1998). Education in the Ever-Changing World. Final Report and Proceedings of the Second International Congress "Ethical, Legal and Societal Challenges of Cyberspace" (pp. 251-259). Monte-Carlo: UNESCO.

Kinelev V. (2000). Information Technologies in Educational Innovation for Development: Interfocused Global and Indigenous Knowledge. Raja Roy Singh Lecture. Paper presented at the Sixth UNESCO-ACEID International Conference (pp. 923). Bangkok, Thailand. Retrieved from unesdoc.unesco.org/images/0012/001264/126427e.pdf 
Kinelev V. (2003). The Use of ICT for Capacity Building in Science via Education. Keynote Lecture. International Conference on IT Based Capacity Building in Science. Okinawa, Japan. UNESCO Institute for Information Technologies in Education.

Kinelev V. (2003). Education for Evolving Societies. World Summit on the Information Society (WSIS). Round table discussion "Education and Knowledge Societies". UNESCO Institute for Information Technologies in Education (pp. 10-16.).

Kinelev V. (2004). Education via Internet. Higher School (p. 791). Moscow.

Kinelev V. (2007). Education for the Information Society. Open Education, 5, 46-57.

\section{About the Author}

Vladimir Kinelev

Head of UNESCO Chair "Knowledge Society and New Information Technologies," Academician of Russian Academy of Education, Doctor of Technical Sciences, Professor.

E-mail: v.kinelev@gmail.com 